\title{
High school students' socialization features under certain conditions in a secondary school
}

\author{
Inessa Kuzheleva ${ }^{1, *}$ and Maxim Kuzhelev ${ }^{1}$ \\ ${ }^{1}$ Don State Technical University, Gagarina sq., 1, Rostov-on-Don, 344003, Russia
}

\begin{abstract}
This article examines high school students' features of socialization in a comprehensive school, as well as the terms of their socialization efficiency. The age characteristics of high school students are also considered, the main features that help to form socialization are identified. The approaches and main characteristics of socialization are determined. Based on the characteristics identified in the course of the study, the conditions were determined under which the formation of socialization would be more successful. It was revealed that the personality of the teacher and his successful intraschool development play an important role and are an essential condition for the successful socialization of the personality. It is mentioned, that the educational process management is necessary as not only the teacher, but the student as well plays an important role in socialization. Moreover, the student learns to independently determine his goals and objectives.
\end{abstract}

\section{Introduction}

The analysis of psychological, pedagogical, sociological and philosophical literature allows us to assert that at present certain prerequisites have emerged that make it possible to further comprehend the actualized plane of research.

The problems of socialization of high school students are being developed by many researchers. In the psychological and pedagogical field of scientific knowledge, the means and factors of socialization of the individual (Juan Manuel Moreno-Manso [1] Rosemary Wette [2], etc.), the development of social competence of the individual, including in senior school age (CarolineJunge, EmiliaRomppanen, MarieKorhonen, Raili KSalmelinc, KaijaPuura, IlonaLuoma, etc.), the age periodization of this process was carried out (L.S.Vygotsky, Barsukova O, Mozgovaya, N, Sherbina, E; Shestopalova O, and others), the dominant spectrum of needs was explained, motives, aspirations and value orientations of the socializing personality in the period of early youth (P.I. Ananchenkova, L.I.Bozhovich, D.N.Dybrovin, D.I.Feldstein, P.V. Fokina, A.N. .), the effectiveness of pedagogical influence on the process of socialization of a person in senior school age has been proved (Belousova A, Kozhukhar, G) [3] (. the ability to introduce health-saving technologies( Gafiatulina, Natalya, Kh; Makadey, Lyudmila I; Gluzman, Iuliia, V) [4]

Methodological basis of the research:

Corresponding author: inessa_kuzheleva@mail.ru 
- personal-activity approach in organizing the high school students socialization during the process of learning;

- competence- approach [5];

- praxeological approach;

\section{Features of the formation of socialization of high school students}

The senior school age stage refers to the age period from 15 to 18 years old. This age group is characterized by dual features: during this period, schoolchildren are characterized by both youthful and adolescent features. One of the main psychological characteristics of early adolescence is an aspiration for the future. A personality in senior school age develops in a new social situation for it, which includes the process of completing schooling and an independent choice of a further life path. The senior student begins to design professional and life plans, his daily activities are associated with complex internal work to build a system of life meanings. Scientists have found that relative calmness at this time in physical development [6] (in comparison with adolescence) allows the inner world of a person to develop intensively and form a unique problematic field of personal development as a relatively stable combination of many problems that have existed for a long time (a number of months), which stand in front of the individual and require a solution. The core of these life meanings is problem fields, which include: problems with appearance, problems in emotions, feelings, will, problems in relationships with parents and relatives, such as misunderstanding, criticism [7] or physical punishment [8], problems at school or everyday problems.

Success in living through these problematic fields determines the asquisition of one's own personal growth characteristics, the realization of vital plans, consciousness of one's own life, and solving burning problems. This process is fundamental in the practical inclusion in various spheres of life. Analysis of the characteristics of this age allows us to talk about its importance in the formation of human morality. During this period, the subject gains the ability to reason about behavior based on his own criteria, based on respect for a democratically made decision or on respect for human rights.

The period of early adolescence [9] is a separate stage for the spiritual formation of the individual. Within its boundaries, the world outlook, legal consciousness and political activity of the individual are intensively formed. Potentially, a person goes to new boundaries of understanding the world, actively assimilating, reproducing social content (norms, social roles), which corresponds to the socialization process terms, and at the same time transforming this social content into a semantic one.

In this age period, the mechanism of identification-isolation receives a new development. It was in youth that the ability to "feel" into the state of other people, the ability to empathize, was sharpened. Boys and girls strive to identify with themselves, with peers of the same sex, and also with each other. The identification mechanism refines the feeling of personality, making it richer and at non-linear.

However, the main characteristic of this age period is isolation, separation of oneself from the rest, the formation of one's own I. This occurs in order to strengthen the sense of personality through reflection, preserve one's individuality, and realize one's claims for recognition.

Formed at this age and variability of living space, in which adolescents can experience both strong feelings and superficial in love relationships. Due to the identification and isolation inherent in adolescence, young people are immersed in such ambivalent states. The ways young people behave in love relationships, the extent to which they adequately solve problems caused by success and failure in love, depend on their spiritual qualities and 
the depth of moral self-awareness development.

Identification and separation are an essential part of the conscious construction of communication methods, in which boys and girls experience many difficulties.

The development of character traits also has its own characteristics, since during this period the level and nature of sociability increases, ease in communication with people appears, dominance, persistence and competition, at the same time impulsivity and excitability decrease. In senior school age, the separate, relatively independent development of relationships between children and peers and adults continues. Interpersonal communication takes longer than in adolescence, with most of the time young men spend communicating with their peers. Peer relationships play an important role here, especially on social media. [10] Peers who are close friends are recognized and respected.

Adolescence is an important stage in the development of mental abilities, since the stage of formal operations is already completed and mental operations are performed without any specific support. Logical memory is actively developing, the thought process of memorization in older schoolchildren is the establishment of logical relations within the memorized material, and recall is associated with the restoration of material according to such relations. The subject acquires a number of cognitive qualities that make them perfect and flexible.

In general, cognitive processes at this age reach such a level of development that boys and girls are almost ready to perform all types of mental work, including the most difficult level. Along with cognitive abilities at this age, creative abilities are actively developing, which help to overcome the routine in ideas, to search for unusual connections and analogies.

A qualitative leap is also characteristic of the motivational-semantic sphere of the individual, and self-awareness, and the emotional-volitional sphere. At this age, a number of character traits are especially sharply emphasized, which can lead to psychological trauma or deviant behavior.

The success of socialization is also determined by the motivation to learn. Social motives in senior school age also develop in a number of directions. Thus, the role of general social motives of civic duty and return to society is growing. But far from all schoolchildren they are developed in the proper form, which manifests itself in social immaturity, dependency, consumer attitude towards the family and society as a whole, unwillingness and inability to contribute to social practices.

Since in the period of senior school age a person first comes into direct contact with society, then his main task is to solve social problems: the choice of a profession, the acquisition of a certain social status. Therefore, special research should be made in the focus of the social aspect of the subject's entry into adulthood and changes in the social situation of the student's development.

Working in a team, active position in life, resolving conflicts, using various technologies to support learning, setting goals and solving cognitive tasks - these are the most essential abilities in pedagogical process [11]. Involvement and attention to environmental problems are also of great importance. They are necessary for personality development in senior school age [12], etc. All above mentioned are valuable components of socialization. The personality of the teacher plays a direct role in learning, leading to a decrease or increase in motivation. [13] Formation of socialization of schoolchildren means a gradual replacement of just cognitive activity with a socially significant one with the correct change of needs, goals, means, actions and behavior.

Nevertheless, interest in knowledge or cognitive activity dominates which becomes deeper and affects not only the educational process essence, but also the foundations of sciences. Educational and cognitive motives as an interest in methods of obtaining knowledge are improved and are manifested in an interest in theoretical and creative 
thinking. High school students are interested in the work of school scientific communities, creative teams, in the classroom they widely use research methods. At the same time, high school students are interested in ways to make the effectiveness of cognitive activity better, which confirms their interest in manuals, classes and tasks related to culture and the rational organization of mental work. At this age, the unity of the procedural and effective motivations of learning is already manifested. Particular emphasis is placed on selfeducation and self-esteem. That is, there is a desire to actively analyze their activities, identify the strengths and weaknesses of their educational work, the desire to understand and express their individuality in the educational process.

The creation of conditions for the effective formation of socialization among students is manifested in accordance / non-compliance with a certain ideal, towards which all its participants are oriented. On the one hand, this ideal can be defined as a graduate model, which reflects the qualitative characteristics of the competencies enshrined in the Federal State Educational Standard. expanding the way of thinking, general intelligence, supporting the desire of students for scientific and project activities, introducing them to cultural and spiritual and moral ideals, traditions, holidays, etc. Thus, the goal of an educational institution is reduced to the complex development of a personality that corresponds to a specific socialization norm at the moment.

The problem of high school students' socialization formation involves creating conditions in general educational organizations that will allow:

- comprehensively develop the personality of students;

- to provide maximum freedom in choosing forms and means of self-realization in various areas of educational activity;

- to form a positive attitude towards educational activities, cognition and selfknowledge, which will be in demand for further personal self-development and selfeducation, growth of self-organization skills;

-develop adequate self-esteem.

The problems of building the socialization of students in an educational institution are complex and interdisciplinary. Activity is one of the main areas of personality socialization. Activity is a way of human existence, therefore, the ability to act is the most important social quality that makes a person a subject of active social life. The teacher's basic orientation is also very important as well as interaction with students and other participants of the pedagogical process. The tasks of teachers include helping the teacher in realizing himself as a person who is capable of self-development, self-determination and selfrealization. It is the personality-activity approach that presupposes the creation of conditions for ensuring the subject position of the student in the educational process, for the independent determination and choice of spheres of activity, reflection of its results; to transform socio-cultural knowledge obtained in educational activities into appropriate skills; to build open relationships between teachers and students on the basis of trust, dialogue, allowing students to self-reveal and self-actualize. In order to build educational and educational activities so that students can actively apply the obtained theoretical knowledge to solve practical social problems, it is necessary to actualize the competencebased approach, when the educational process is aimed at results. The developing environment is the necessary condition for the competence-based approach realization, which is the immersion of students in any practical orientation of school education.

In this aspect, the provisions of the praxeological approach are very interesting, which allows and even requires considering knowledge and practice in unity.

So, the personality-activity, competence-based and praxeological foundations of building the educational process are able to create an environment that ensures the development of socialization of high school students through:

- Content and education guidelines variability; 
- the educational process modernization;

- the conditions for the manifestation of subjective experience, the development of selfawareness, skills of self-reflection and other personal properties that ensure selfdevelopment, life and professional self-determination, the design of the content of their education and their future life;

- new approaches to the educational process organization adaptation;

- changes in the life of students in an educational institution by emphasizing the importance of self-organization, activities within the framework of practice-oriented associations, personal involvement in solving their own life problems, etc. Thus, the features of high school students socialization formation can be represented schematically in Fig. 1.

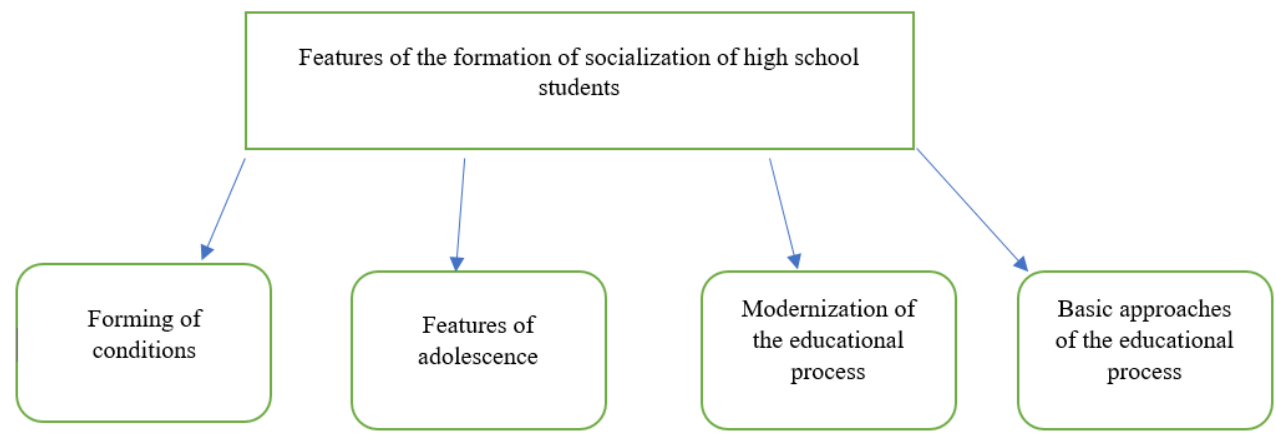

Fig. 1. Features of the formation of socialization of high school students.

The specificity of socialization is manifested:

- in the ability of a person to orient in the neighboring socio-cultural environment; the capability to express the selected values in concepts, justify one's choice, evaluate what is happening in the focus of such values, determining the value foundations of the existential terms, social status; the ability to express their cultural and other self-identification, social orientation of behavior;

- in constructive thinking, the ability to understand the particular in general and the general in the particular, solve socially oriented problems and vary solutions which depend on specific circumstances; display sincere interest in social partners, in scientific knowledge, methods of cognition, research methods, readiness to increase the educational level;

- in the ability to self-determine in thinking, will, faith and feelings, moral foundations; the ability for introspection and self-esteem; independent choice of a decision, personal responsibility for what is taken and done, creative new socially significant options modeling for communication; self-governing, self-education, independence;

- in the availability of interaction technique, the ability to work in a team; to establish adequateness, to create the climate of trust; the ability to constructively and efficiently resolve conflicts.

\section{The environment for successful socialization of high school students}

Based on the analysis of the research issue, we made the conclusion that the set of purposefully created conditions that shape the socialization of schoolchildren should be an integral system that allows students to form values and models of socially successful solutions to life problems. 
The school environment allows us to designate the conditions that allow it to design, develop, and manage it in accordance with the characteristics of the socialization formation of high school students. In other words, conditions are certain circumstances that optimize the process of socialization of high school students and are aimed at achieving effective results in the process of socialization, see Fig. 2.

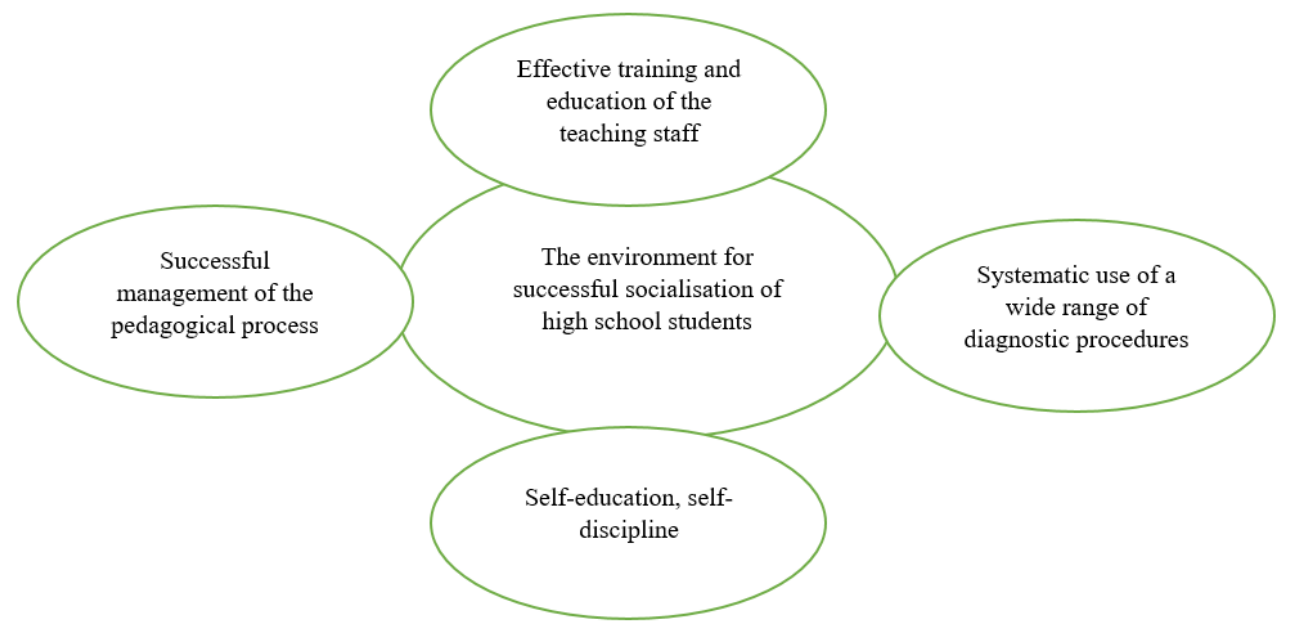

Fig. 2. The environment for successful socialization of high school students.

One of the necessary terms of successful education is a teacher-training one [14]. So, creating of friendly atmosphere for speeding up the process of training teachers [15], as well as the readiness of the teachers themselves to create such an environment that allows the most effective form of socialization of high school students. are badly needed. [16]. Namely, the ability and desire to master new technologies and approaches that contribute to the socialization of high school students. Study the latest research in the field of socialization, develop and implement new modified programs, improve teamwork in the workplace, share experience at master classes, conferences, seminars. Also, a condition can be called the appropriate control [17], i.e. constant control of changes in students for the socialization formation of high school students successful implementation, various methods and forms of teaching and educational work effectiveness, as well as the way it is presented to high school students. This control should include a wide range of diagnostic procedures and indicators.

It is also worth noting the condition under which the teacher is able to manage the educational and cognitive process, which allows increasing the educational opportunities of the social environment [18], and the student to manage the self-educational process. The core of this condition is the direct management of the process of the student's personal development and the formation of certain competencies in him.

Evaluation of the results of this process makes it possible to objectively initialize the assessment of the effectiveness of socialization of students, taking into account his personal characteristics.

In this regard, there are requirements for the effectiveness of this condition. For the ability to manage the pedagogical process successfully, it is necessary:

1. to take into consideration every part of educational process : aims, data, decisionmaking, communication, monitoring; etc when defining indicators of the socialization of senior students effectiveness and their application in constructing the process of socialization; 
2. to coordinate structural units in the activities of managers, pedagogical stuff, teachers interaction, methodological groups, etc. in solving and correction of socialization problems;

3 .to adapt the management model to changing socio-economic and pedagogical conditions, the needs of consumers of educational services (high school students, parents, professional educational organizations)

4. involvement of teachers, managers, qualified specialists in decision-making in the construction, maintenance of functioning, and tracking the effectiveness of socialization of senior students;

5. a combination of the principles of management and self-government both for the system as a whole and for each subject separately in order to solve the problems of socialization of students and the formation of their personality.

At the symposium of the Council of Europe in 1996, an indicative list of competencies was determined, which are the requirements for a person of modern culture:" 1. Political and social competencies such as the capacity to accept responsibilities, to participate in group decisions, to resolve conflicts in a non-violent manner, and to play a part in running and improving democratic institutions. 2. Competencies relating to life in a multicultural society. In order to check the resurgence of racism and xenophobia and the development of a climate of intolerance, education must "equip" young people with intercultural competencies such as accepting differences, respecting others and the capacity to live with people of other cultures, languages and religions. 3. Competencies relating to the mastery of oral and written communication, which are essential for work and social life to the point that those who lack them are henceforward threatened with social exclusion. In this same register of communication, the mastery of more than one language is taking on growing importance. 4. Competencies associated with the emergence of the information society. The mastery of these technologies, the understanding of their applications, strengths and weaknesses, and the capacity for critical judgment with regard to information disseminated by the mass media and advertisers".[19]

Self-education is like a complex cultural process of development, cultural activity of the subjects of the educational process, cultural space that provides interaction between education and other social spheres, primarily culture, a socio-cultural system that has certain functions.

By creating conditions for the socialization of high school students in the process of mastering cultural patterns of life, taking into account and building the cultural and educational space, the school is able to form the type of its life activity, influencing the adaptation of students to the modern world, their interests, personal meanings, and also to correct the pedagogical activity of the teacher

The described conditions as a specially organized environment stimulate the development and self-development of each subject included in it, since they are aimed at the personal and creative development of both high school students and teachers.

\section{Conclusion}

Taking into consideration the high school students' age, the features characterizing a given age, it is of great importance to create certain terms that would help them successfully selfactualize, self-develop. One of the key mental individualities of early adolescence is striving for the future. The individual in senior school age develops in a new social history, which includes, as a process of finishing school studies, for example, an autonomous choice of the next actual path. An adult teenager begins to project actual intentions, his mental life is associated with difficult inner work to build a system of actual contents. To educate a person of culture, to create an environment aimed at the formation of an active cognitive interest in cultural values, at the formation of the ability to creatively use the knowledge 
gained to solve moral and social problems. This is directly related to solving the problem of developing positive relationships between the subjects of the educational environment of the school. At the same time, successful socialization is possible only if certain conditions are met, which are created by all participants in the educational process. Socialization cannot be formed independently, therefore, students need help and attention from teachers, help the student to self-determine by setting certain goals and objectives.

In general, the process of socialization is an integrated approach, which involves the process of mastering of such skills and abilities by a person that help to form social maturity and self-awareness. High school students are ready for social interaction, in which they find a constructive approach to solving problems that can arise. One of the important characteristics of socialization is the awareness of the value and meaning of sociocultural activity, in the ability to build productive relationships with all participants of this process. In the process of socialization, high school students become more responsible for the results of their social interaction, in self-determination with the individual educational trajectory, choice of profession and a certain significant social status.

Education is not the only means of human socialization, but, undoubtedly, one of the most important, because it is a certain social systematized technology of intensive immersion of a person in the socio-cultural space.

Forms of socialization at school are the same forms of education and upbringing, organization of training and upbringing, educational and upbringing work, which solve the problems of including high school students in social practice, shaping their social qualities, assimilating social experience and realizing their own essence through the implementation of a certain role in practice.

The choice of the content, necessary methods, and techniques of training and education are very important. Successful students' socialization formation gives them various ways of cognitive activity. The unity of various educational forms and methods in the high school environment - gives the teacher possibility for building a flexible, and effective trajectory of students' socialization.

\section{References}

1. J. Manuel Moreno-Manso, J. Godoy-Merino, Á. Suárez-Muñoz, E. García-Baamonde, Children and Youth Services Review 35, 865-870 (2013) doi.org/10.1016/j.childyouth.2013.02.009

2. R. Wette, C. Furneaux, SYSTEM 78, 186-200 (2018)

3. A. Belousova, G. Kozhukhar, $12^{\text {th }}$ International Technology, Education and Development conference 12, 291-298 (2018)

4. N.Kh. Gafiatulina, L. Makadey, I. Gluzman et al., International Journal of Applied Exercise Physiology, 8, 293-300 (2019)

5. E. Platonova, O. Fedotova, M. Musarskiy, O. Igumnov, E. Kuznetsova, 10th international conference of education, research and innovation, 6844-6848 (2017)

6. E. Berezhnaya, V.A. Bondarev, Y.V. Zazulina, N.V. Koloskova, A.V. Strichko, Conference on Future of the Global Financial System - Downfall or Harmony 57, 364370 (2019)

7. Chang Ying-Fen, Journal of Research in Education Sciences 66, 203-230 (2021) doi: 10.6209/jories.202103_66(1).0007

8. V. Rodionova, L. Shvachkina, L. Kuznetsova, Modern Journal of Language Teaching Methods 8, 218-232 (2018) 
9. O. Barsukova, N. Mozgovaya, E. Sherbina, O. Shestopalova, 14th International Technology, Education and Development Conference, 2893-2897 (2020)

10. R. Sanchez, A. Leonardo, Espacios en Blanco-Serie Indagaciones 31, 196-210 (2021) doi: 10.37177/unicen/eb31-296

11. N.A. Hawk, V.W. Vongkulluksn, Kui Xie, M.A. Bowman, Journal of computer assisted learning (2021) doi: 10.1111/jcal.12547

12. S. Santilli, I. di Maggio, M.C. Ginevra, N.L. Salvatore Soresi, Sustainability 12, 9048 (2020) doi: 10.3390/su12219048

13. S. Khalilzadeh, Ali Khodi, Current psychology 40, 1635-1650 (2021) doi: 10.1007/s12144-018-0064-8

14. T. Mikheeva, E. Murugova, Y. Morozova, V. Demchenko, 14th International Technology, Education and Development Conference, 1211-1215 (2020) doi: 10.21125/inted.2020.0417

15. Liang Huang, Ting Zhang, Yating Huang, Studies in Educational Evaluation 66, (2020) doi.org/10.1016/j.stueduc.2020.100893

16. Y.S Morozova, I.G. Kuzheleva, Innovative Technologies in Science and Education (2020) https://doi.org/10.1051/e3sconf/202021022026 (2020)

17. T.B. Mikheeva, E.V. Murugova, SHS Web Conf. 70 (2019) doi: https://doi.org/10.1051/shsconf/20197007003

18. A. Khuziakhmetov, R. Nasibullov, Proceedings of 6th World Conference on Educational Sciences, 191, 843-847 (2015) doi: 10.1016/j.sbspro.2015.04.385

19. https://ec.europa.eu/education/policies/school/key-competences-and-basic-skills_en 